\title{
Psychology of pain
}

\author{
KENNETH D. CRAIG \\ M.A., Ph.D.
}

Department of Psychology, University of British Columbia, Vancouver, B.C. Canada V6T 1Y7

\section{Introduction}

To the sufferer, pain is a vital reality. While fully aware of this, the scientist and practitioner must also recognize that efforts to understand and manage pain can be only as good as the available theoretical models. Recent decades have seen concepts of pain increasingly embrace psychological models (Merskey and Spear, 1967; Sternbach, 1978; Melzack and Wall, 1983). The definition of pain adopted by the International Association for the Study of Pain (1979) describes pain as 'An unpleasant sensory and emotional experience associated with actual or potential tissue damage, or described in terms of such damage'. The emphasis on experiential qualities and psychological processes has major implications. First, the knowledge-base for this complex phenomenon has expanded, and we have begun to address questions about the personal meaning of pain to the sufferer, relationships between subjective experience and overt expression, and decision strategies for coping with personal discomfort. Second, the evidence that pain experience and expression are strongly influenced by personal factors and the social contexts of patients' lives has resulted in new strategies for pain assessment and management. Strategies have emerged that have proved successful in preventing adverse reactions to acute pain, and for working with patients with chronic pain (e.g., Barber and Adrian, 1982; Fordyce, 1976; Sternbach, 1974; Turk, Meichenbaum and Genest, 1983).

The impetus for a better understanding of the psychological component of pain derives from a variety of sources. The substantial range of individual responses to comparable tissue damage has demanded explanation. Reactions can range from impassive stoical forbearance to highly dramatic and hysterical behaviour. Considerable evidence now supports the view that each individual's experience of pain, and the manner of expression, can be explained only as a product of the sufferer's personal background, the interpersonal context in which pain is experienced, the meaning the experience has for the individual, as well as by the sensory input provided by noxious stimuli (Craig, 1980; 1983).
Many chronic pain syndromes, as well as some reactions to acute pain, can only be understood by incorporating psychological variables into explanatory models. Exclusively sensory and predominantly biophysical explanatory models, that emphasize treatment of underlying pathophysiological processes, have proved inadequate, with large numbers of patients who do not benefit from care based on this model. While the majority of painful injuries heal through spontaneous recovery and medical intervention, Bonica (1983) has estimated that one-third of the population suffers some form of recurrent or persistent pain.

\section{Cognitive processes in pain}

The study of cognitive processes underlying all patterns of behaviour has enjoyed considerable enthusiastic development in the past decade (Anderson, 1980; Neisser, 1976; Weimer, 1982), with many of the models of immediate relevance to the study and management of pain. The concepts fall logically into two categories: those concerning the form and structure of cognitive processes and those descriptive of the contents of thoughts.

Most important in regulating painful experience are those cognitive structures which organize and impose order upon experience. They govern the patterning of attention, memory, decision-making, and other self-regulatory processes. Inherently tacit and superordinate to the contents of experience, the cognitive processes impose limits on the concrete particulars of experience (Mahoney, 1983; Rosenthal and Zimmerman, 1978). From this perspective, all experience is an active construction of the nervous system with the biological constraints dictating how people attend to their environment, the assimilation and organization of experience, and decision-making strategies.

Understanding how people serve as active participants in the nature of their experiences has provided a general theoretical framework for a variety of powerful pain phenomena; namely, the impact of belief systems, placebo and expectancy effects, the 
role of attention and distraction and perceived control phenomena.

Belief systems attach meaning to experience. Pain usually signifies real or potential tissue damage and life-threat, and provides a powerful incentive to understand what is happening to the individual. Both the person in pain and the health professional ordinarily interpret pain as the cardinal symptom of disease or injury. The sufferer can be expected to devote considerable effort towards seeking out and understanding the origins and nature of the experience, as well as surrounding circumstances, and to enlist the best possible personal and social resources to master the threat.

The experience differs with the nature of the pain (Sternbach, 1974). Acute pain, with its usual course of rapid onset and reasonably short recovery period, is associated with a search for information about what is happening and how distress can be controlled. Chronic pain in its unremitting, recurrent, or progresssive patterns is often associated with discontinuing the search and acceptance of the invalid role.

Pain associated with specific injuries and diseases may have special significance for individual patients that deserves consideration. Burns or facial damage that is disfiguring may provoke psychological trauma. Angina pain has acquired special meaning in our medically-sophisticated Western culture. Musicians and athletes may encounter special problems with painful limb injuries that threaten their ability to maintain control over their lives.

Further variations in belief systems and patterns of thinking about pain and illness have their origins in the family, peer groups and the community (Craig, $1978,1983)$. Both information and the strategies used to collect, process and apply information are primarily drawn from countless exposures to the activities of others (Rosenthal and Zimmerman, 1978). Here the individual learns to recognize, interpret, and evaluate what become normal and anomalous somatic sensations. Socialization practices provide the basis for the transmission of beliefs, normative standards, and conceptual skills of the community. The familial and cultural precepts are immediately available, tend to be consistently applied by others, and are supported by social sanctions to conform. The individual can readily learn what is likely to generate pain; what sensations should be experienced as alarming; how different injuries and diseases are likely to feel; and cognitive, behavioural, and social skills useful in minimizing personal distress. Cross-cultural studies effectively demonstrate the variability that has emerged in different societies for recognizing and caring for states of disease and injury (Craig, 1980). Similarly, styles of pain complaint tend to be common within families (Craig, 1978). For example, children who become particular problems for dentists
(Kleinknecht, Klepac and Alexander, 1973) or children with nondiagnosable chronic abdominable pain (Barr, 1983) and pain patients in general (Mohamed, Weisz and Waring, 1978) tend to come from families in which other family members present with anomalous pain complaint. One can legitimately refer to 'pain prone families'.

\section{The placebo response}

Recognition of the important role of belief systems in determining pain experience and behaviour was compelled by the placebo effect (Beecher, 1965; Critelli and Neumann, 1984). Inert chemicals and treatments that have been determined to be nonspecific, or even deleterious to health, frequently prove to be strikingly effective as analgesics when administered by enthusiastic, credible proponents of their efficacy (Shapiro, 1971). Newer therapies also enjoy similar social facilitation effects since they commonly surpass other therapies in comparative effectiveness. It has become common practice to test all new drugs and other forms of therapy by comparing them to pharmacologically inert placebos or non-specific treatment. Client improvement alone has been judged to be an inadequate criterion for therapeutic effectiveness of a drug since it may be mediated by psychological factors other than theo treatment or remedy's specific action.

Unfortunately, with the discovery of specific drug and surgical pain-relieving techniques, placebos acquired negative connotations. They became characterized as a nuisance and clinicians declined to use them with patients. However, at present their salutary effects are being recognized. When properly used, they do reduce pain without the harmful side effects that accompany many analgesic drugs (Meinhardt and McCaffery, 1983). We are only now discovering the reasons why they work, be it belief systems, expectancy, suggestion, or other social influence factors such as context, therapist activities, or persuasion. The non-specific is becoming specific. While placebo drugs may be inert, the psychological processes that mediate placebo effects are active, powerful, and amenable to systematic application.

Even when demonstrably effective, biologicallyoriented, analgesic interventions are used, psychological factors may have complementary or synergistic effects. Norton et al. (1984) found that positive beliefs in the effectiveness of acupuncture were associated with reductions in pain severity beyond those elicited by acupuncture in the absence of positive beliefs. Chen and Chapman (1980) found that cognitive coping strategies facilitated the analgesic impact of aspirin as assessed by evoked brain potentials.

Irrational and self-defeating thinking has been shown to play an important role in the genesis of 
both unreasonably controlled and excessive responses to painful injury and disease. Given that pain and illness are fraught with highly salient personal meaning, the impact of inaccurate or false beliefs may be considerable. The classic illustration was provided by Beecher (1959) who contrasted the reaction patterns of World War II American soldiers wounded during the Italian invasion with civilians who had sustained comparable wounds during surgery. The former required substantially less care and analgesic medication, suggesting that escape alive from battlefields represented a dramatic source of relief from stress, or the proverbial 'ticket-home'. In contrast, the injured civilians had to endure major crises and disruptions to their lives precipitated abruptly by the accidents.

\section{Pain and depression}

Recent evidence confirms a role for cognitive distortions in chronic pain patients who display psychological problems. Lefebvre (1981) found that the cognitive distortions characteristic of clinically depressed patients were also descriptive of the thinking style of chronic low back pain patients who become depressed. The chronic pain patients were generally negative in appraising life experiences and displayed markedly constrictive and negative ideals about the impact of their pain problem on their lives. This would be consistent with findings that pain patients who acquire a conviction that they will remain chronic invalids are substantially more difficult to treat (Sternbach, 1974; Pilowsky, 1980). Pessimistic and self-critical thoughts and preoccupations appear to produce considerable disruptive irrational distress and impair performance by diverting attention from life-tasks to further selfevaluative concerns (Turk, Meichenbaum and Genest, 1983).

Perceived mastery over threat has proved to be a critical determinant of the severity of stress reactions (Neufeld and Kuiper, 1983). Both favourable personal histories and planned training in cognitive coping strategies may result in a 'sense of mastery' that may 'inoculate' against stress (Turk et al., 1983). Bandura (1982) has observed that perceived selfefficacy, or perception of a personal capacity to control a threatening event, lies at the core of all therapeutic effects. People who enjoy confidence in their abilities to cope with pain would be expected to experience less anxiety and fewer feelings of helplessness.

Perceived self-efficacy would be expected to vary with the nature of the noxious assault. The sudden onset of a traumatic injury or precipitous disease would require an extraordinary background of preparation if the suffering person were to respond with a dispassionate sense of mastery. In contrast, pain syndromes that persist over time are more likely to provide opportunities for considered appraisal and therapeutic intervention designed to provide the cognitive and behavioural skills that accompany a sense of mastery (Gottlieb et al., 1977).

\section{New strategies}

An examination of specific cognitive mechanisms has improved our understanding of pain and led to innovative treatment strategies (Tan, 1982). Attention, retention and decision-making, have been demonstrated to be important in investigations of pain (Craig, 1983). A focus upon attentional mechanisms has been particularly productive. One can attend to only a limited subset of internal or external events at a given time. Pain tends to be pre-eminent in its capacity to command attention (Chapman, 1978). It narrows the focus of attention to immediate events. However, despite the salience of noxious events, substantial evidence supports the position that distraction can serve to reduce the severity of pain (Turk et al., 1983).

The amount of stress experienced also will be a function of appraisals of personal and external resources and support systems (Neufeld and Kuiper, 1983). Life history and the immediate social context provide the basis for this evaluation. With pain recognized to be a more ambiguous experience than sensory-specificity models had us believe, prior personal and social experiences (Craig, 1978, 1983; Weisenberg, 1983) assume greater importance. In essence, people must acquire an awareness of their bodies, learn to recognize anomalous somatic states, and discover when and how to seek help. People readily recall distressing and painful events with miminal cues (Hunter, Philips and Rachman, 1979) and benefit substantially from preparation for painful events that provides information about how they are likely to feel, what the trajectories of discomfort and recovery are likely to be and which cognitive and behavioural coping skills minimize distress (Fagerhaugh, 1974; Melamed and Siegel, 1980).

Turk et al. (1983) review considerable evidence consistent with the position that coping strategies, attentional distraction, and other cognitive-behavioural intervention strategies can reduce perceived discomfort and increase pain tolerance. These authors also provide the most comprehensive cognitive/behavioural treatment programme available.

The foregoing review has stressed the position that pessimistic and self-critical thoughts and preoccupations can produce disruptive emotional distress and enhance pain. The complexities of interactions among cognitive, emotional and behavioural aspects of pain are, however, more complex. Pain, anxiety, 
and depression can lead to the processing of incoming information in a destructive manner. Strong tendencies have been reported for depressed moods to trigger memories of sad and unhappy events (Teasdale and Rezin, 1978) and for anxiety to enhance the interpretation of innocuous events as dangerous (Rachman, 1980). People suffering from pain can be expected to be biased towards anticipating the prospect of further unfortunate events and to scanning selectively their external environments and personal experience for threats. From this perspective, those powerful behavioural intervention strategies that focus directly on affective states rather than cognitive changes also assume a major role in pain management (Craig and McMahon, 1983).

\section{Emotional components of pain}

The most dominant contemporary model of pain, gate-control theory (Melzack and Wall, 1965, 1983), has assigned a major role to those affective and motivational processes which were overshadowed by the emphasis on sensory physiology in earlier models (Craig, in press). Focusing attention upon the distinctly unpleasant, affective qualities of pain, and the roles of anxiety in acute pain and depression in chronic pain (Sternbach, 1974), has had several benefits. Our concepts of pain processes now coincide more closely with patients' experiences as they report them. The feelings of fear, punishment, anguish and despair tend to be major preoccupations, and new avenues for understanding the nature of pain have also opened up.

There is now an established neurophysiological basis for the different psychological components of pain with the neurophysiological mechanisms for emotional states increasingly well established. Melzack and Casey (1968) proposed that (a) sensorydiscriminative qualities are primarily determined by activity in the rapidly conducting spinal systems; (b) motivational-affective qualities are subserved by activities in the reticular and limbic structures that are predominantly influenced by slowly conducting spinal systems; and (c) neocortical and higher central nervous system processes exert control over activity in both the discriminative and motivational systems. The recent identification of neurochemical substrata for pain, for example, the action of endogenous opioid peptides in analgesia, further complicates our understanding of the interaction of the neurochemical and neurophysiological substrate of the psychological components of pain but suggests exciting therapeutic possibilities.

Affective qualities of clinical pain vary in accordance with the important distinction between acute and chronic pain states (Bonica, 1983; Sternbach, 1978). Acute pain is usually characterized by tissue damage, commands attention, disrupts behaviour, precipitates action designed to reduce the distress, $\stackrel{\varnothing}{\Omega}$ and has strong affective qualities, usually character- $C$. ized by fear and anxiety. In general, greater anxiety is $\overrightarrow{\vec{F}}$ associated with greater pain, although exceptions have been reported (Craig, in press).

\section{Acute versus chronic pain}

By definition, acute pain is transient and decreases $\approx$ as tissue damage heals. Chronic pain, in contrast, $\vec{\circ}$ persists beyond the time healing should have taken place. The pathophysiological basis for chronic pain $\vec{\omega}$ may be highly variable. The pain may either signal a persistent or progressive disease or a condition that $\stackrel{6}{7}$ has neither real nor impending tissue damage. In 3 . contrast, the psychological consequences of chronic: pain are consistent. Bonica (1974) described chronic pain as exclusively malefic because it is powerfully $\vec{O}$ destructive of the physical and psychological well $\omega_{W}^{\infty}$ being of the individual and his or her family and

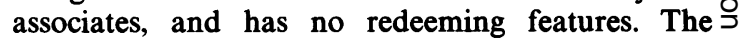
distinction between the two syndromes has become $\overrightarrow{ }$ so clear that it is now recognized that treatment for $\mathbb{\Phi}^{\circ}$ acute pain is contraindicated with some types of $\mathscr{\Phi}$ chronic pain. Certain people suffering from the latter 3 become at risk for more serious problems if strong $\Phi$ analgesics are prescribed, extensive convalescenef $\overrightarrow{0}$ and inactivity are recommended, and there is escape $\infty$ or release from ongoing life responsibilities such work or family routines (Fordyce, 1976; Sternbach, 1974).

\section{The language of pain}

Perhaps the most useful systematic measure of $\overrightarrow{\overrightarrow{0}}$ affective qualities of pain yet available has been the 3 McGill Pain Questionnaire (Melzack, 1975, 1983). This instrument permits patients to describe their: pain on a number of qualitatively distinct dimensions of experience. The development work on the questionnaire suggested three main dimensions: sensory, affective, and evaluative. Construct validity studies tend to confirm the validity of distinctions among 0 these three components but suggest a somewhat more $₹$ complex structure (Reading, 1983). Emotional quali-윽 ties appear to represent the major source of variation $D$ in people's descriptions of their painful experiences (Crockett, Prkachin and Craig, 1977; Leavitt, Garron N and Bielauskas, 1978). Gracely, McGrath and Dub-o ner (1979) have developed useful unidimensional $\tilde{}$ ratio scales of sensory, affective, and pain intensity that simplify the task of verbal pain description buto do not search for the subtle nuances of differencese among forms of pain.

Reports of affective qualities have assumed con- $\stackrel{\Phi}{?}$ siderable importance in differential diagnosis. $\mathrm{Pa}-\bar{T}$ 
tients with chronic pelvic pain were found to favour affective and evaluative words to describe their pain, whereas patients in acute pain were prone to use sensory words (Reading, 1983). Leavitt (1983) reported that chronic back pain patients with psychological disturbance endorsed more affective words than patients without psychological disturbance. There would appear to be prospects of developing psychometric instruments that would discriminate between patients for whom psychological problems represented a major component of their pain-related disability and patients for whom psychological difficulties do not represent a serious problem (Kremner and Atkinson, 1983).

Emotional and behavioural disturbances tend to be common in patients with chronic pain, whether there is an identified, sufficient organic basis for the pain or not. Low back pain patients have been reported to have more emotional disturbances as a group than patients with other medical diseases (Leavitt, 1983), and reported affective distress relates to the severity of psychosocial disturbance (McCreary, Turner and Dawson, 1981). Bradley (1983) reported that a group of chronic pain patients, who, through cluster analyses of the Minnesota Multiphasic Personality Inventory (MMPI), were characterized primarily by elevations on scales $\mathrm{Hs}, \mathrm{D}$, and $\mathrm{Hy}$ (the neurotic triad scales), showed greater pain-related disturbances in their daily activities (greater endorsement of affective items on the McGill Pain Questionnaire, reliance on a greater number of analgesic and hypnosedative medications, greater use of health professionals, more sleep disturbance, etc.). Roberts and Reinhardt (1980) found that their behavioural management treatment approach was more successful with patients with substantial organic basis for their pain complaints than for patients without an adequate organic basis.

\section{Behavioural expression}

Pain is a private experience and does not become recognized by others, or become the target of others' caring efforts, until it has some behavioural expression, either through self-report or non-verbal display. Most attention has been devoted to verbal report, but vocal qualities, facial expression, posture, and gross bodily movement convey considerable information of importance to observers in natural and clinical settings (Craig and Prkachin, 1983; Craig and Patrick, in press). This social component of pain is of considerable importance. Pain is frequently a highly public and visible event; qualities which may affect both the sufferer and observer. It is the means whereby sufferers solicit help from others, and allows observers to discover that they may be in personal danger themselves or that the sufferer needs help.
The reflexive qualities of pain expression and observers' reactions suggest strong drives to communicate distress to others and innate propensities to be attentive and responsive when others are in distress.

Of considerable importance has been the discovery that pain behaviours that occur for one set of reasons at the time of onset may persist for a different set of reasons (Fordyce, 1976). In particular, the response of others to the person in distress may perpetuate illness behaviour (as opposed to the original pathophysiological process) beyond the time when healing would take place. This represents an excellent illustration of an occasion in which pain expression does not correspond to a pathophysiological basis for pain. When others respond by providing sympathetic attention, release from work or domestic responsibilities, enforced bedrest or inactivity, and prescription of drugs such as strong analgesics, antidepressants and anxiolytics contingent upon displays of pain, there is an increased risk that the patient may become trapped in the role of a sick person or invalid (Fordyce, 1983). Behavioural management programmes based upon operant learning theory have been attentive to the importance of these contingent consequences (Fordyce, 1984)

Operant pain management programmes appear to mirror the manner in which pain expression and experience come to reflect the individuals' unique familial and ethnocultural background during the course of sociatization. In consequence, there is a satisfying integration between the concepts of pain that have led to effective cognitive/behavioural pain management strategies and formulations of the impact of socialization experience on pain experience and behaviour.

\section{References}

ANDERSON, J.R. (1980) Cognitive Psychology and its Implications. W.H. Freeman, San Francisco.

BANDURA, A. (1982) Self-efficacy mechanisms in human agency. American Psychologist, 37, 122.

BARBER, J. \& ADRIAN, C. (Eds.) (1982) Psychological approaches to the management of pain. Brunner/Mazel, New York.

BARR, R.G. (1983) Pain tolerance and developmental change in pain perception. In: Developmental-behavioral pediatrics. (Eds. M. D. Levine et al.) W. B. Saunders, Philadelphia.

BEECHER, H.K. (1959) Measurement of subjective responses: Quantitative effects of drugs. Oxford University Press, New York.

BEECHER, H.K. (1965) Quantification of the subjective pain experience. In: Pain: Clinical and experimental perspectives. (Ed. M Weisenberg) C. V. Mosby Co., Saint Louis.

BoNICA, J.J. (Ed.) (1974) Advances in neurology, Vol. 4. Raven Press, New York.

BoNICA, J.J. (1983) Pain research and therapy: Achievements of the past and challenges of the future. In: Advances in pain research and therapy, Vol. 5. (Eds. J. J. Bonica, U. Lindblom \& A. Iggo) Raven Press, New York.

BRADLEY, L.A. (1983) Relationships between the MMPI and the McGill Pain Questionnaire. In: Pain measurement and assessment. (Eds. R. Melzack) Raven Press, New York.

Chapman, C.R. (1978) Pain: The perception of noxious events. In: 
The psychology of pain. (Ed. R. A. Sternbach) Raven Press, New York.

Chen, A. \& Chapman, C.R. (1980) Aspirin analgesia evaluated by event-related potentials in man: Possible central action in the brain. Experimental Brain Research, 39, 359.

CRAIG, K.D. (1978) Social modeling influences on pain. In: The psychology of pain. (Ed. R. A. Sternbach) Raven Press, New York.

CrAIG, K.D. (1980) Ontogenetic and cultural determinants of the expression of pain in man. In: Pain and society. (Eds. H. H. Kosterlitz and L. Y. Terenius) Verlag Chemie, Weinheim.

CRAIG, K.D. (1983) Modeling and social learning factors in chronic pain. In: Advances in pain research and therapy, Vol. 5. (Eds. J. J. Bonica, U. Lindblom \& A. Iggo) Raven Press, New York.

CRAIG, K.D. (1984) Emotional aspects of pain. In: Textbook of pain. (Eds. P. D. Wall and R. Melzack) Churchill Livingstone, Edinburgh, London.

CRAIG, K.D. \& MCMAHON, R.J. (Eds.) (1983) Advances in clinical behavior therapy. Brunner/Mazel, New York.

CraIG, K.D. \& PATRICK, C.J. (1984) Facial expression during induced pain. Journal of Personality and Social Psychology (in press).

CraiG, K.D. \& PrKachin, K.M. (1983) Nonverbal measures of pain. In: Pain measurement and assessment. (Ed. R. Melzack) Raven Press, New York.

CRITElli, J.W. \& NeumanN, K.F. (1984) The placebo: Conceptual analysis of a construct in transition. American Psychologist, 39, 32.

Crockett, D.J., Prkachin, K.M. \& Craig, K.D. (1977) Factors of the language of pain in patient and volunteer groups. Pain, 4, 175.

Fagerhaugh, S.Y. (1974) Pain expression and control on a burn control unit. Nursing Outlook, 22, 645.

FORDYCE, W.E. (1976) Behavioral methods for chronic pain and illness. C. J. Mosby, St Louis.

FORDYCE, W.E. (1983) The validity of pain behavior measurement. In: Pain measurement and assessment. (Ed. R. Melzack) Raven Press, New York.

FORDYCE, W.E. (1984) Behavioural science and chronic pain. Postgraduate Medical Journal, 60, 865.

GotTlieb, H., STRITe, L.C., Koller, R., MAdORSKy, A., HoCKerSMITH, V., KLeEmaN, M. \& WaGneR, J. (1977) Comprehensive rehabilitation of patients having chronic low back pain. Archives of Physical Medicine and Rehabilitation, 58, 101.

GRACELY, R.H., MCGRATH, P. \& DUBNER, R. (1979) Narcotic analgesia: Fentanyl reduces the intensity but not the unpleasantness of painful tooth pulp sensations. Science, 203, 1261.

Hunter, M., Phillips, C. \& Rachman, S. (1979) Memory for pain. Pain, 6, 35.

International Association for the Study of Pain (1979) Pain terms: A list with definitions and notes on usage. Pain, 6, 247.

KLeinKNECHT, R.A., KLEPAC, R.K. \& AleXANDER, L.B. (1973) Origins and characteristics of fear of dentistry. Journal of the American Dental Association, 86, 842.

KREMnER, E.F. \& ATKINSON, J.H. (1983) Pain language as a measure of affect in chronic pain patients. In: Pain Measurement and Assessment (Ed. R. Melzack). Raven Press, New York.

LEAVITT, F. (1983) Detecting psychological disturbance using verbal pain. In: Pain measurement and assessment. (Ed. R. Melzack) Raven Press, New York.

LEAVITt, F., GARRon, D.C. \& BiElauskas, L.A. (1980) Psychological disturbance and life event differences among patients with low back pain. Journal of Consulting and Clinical Psychology, 48, 115.

LEFEBVRE, M.F. (1981) Cognitive distortion and cognitive factors in depressed psychiatric and low back pain patients. Journal of Consulting and Clinical Psychology, 49, 517.

MCCreary, C., Turner, J. \& Dawson, E. (1981) Principal dimensions of the pain experience and psychological disturbance in chronic low back pain patients. Pain, 11, 85.
MAHONEY, M.J. (1983) Cognition, consciousness, and processes of personal change. In: Advances in clinical behavior therapy. (Eds. K. D. Craig and R. J. McMahon) Brunner/Mazel, New York.

MeinhardT, N.T. \& MCCAFFery, M. (1983) Pain, a nursing approach to assessment and analysis. Appleton-Century-Crofts, New York.

Melamed, B.G. \& Siegel, L.J. (1980) Behavioral medicine: Practical applications in health care. Springer Publishing Co., New York.

MelzaCK, R. (1975) The McGill Pain Questionnaire: Major properties and scoring methods. Pain, 1, 277.

MELzaCK, R. (E.) (1983) Pain measurement and assessment. Raven Press, New York.

MelZACK, R. \& CASEY, K.L. (1968) Sensory, motivational and central control determinants of pain: A new conceptual model. In: The skin senses. (Ed. D. L. Kenshalo) Thomas, Springfield, Illinois.

MElZACK, R. \& WALL, P.D. (1965) Pain mechanisms: A new theory. Science, 150, 971.

Melzack, R. \& Wall, P.D. (1983) The challenge of pain. Penguin, Harmondsworth, Middlesex, U.K.

Merskey, H. \& SPEAR, F.G. (1967) Pain: Psychological and psychiatric aspects. Williams \& Wilkins Co., Baltimore.

Mohamed, S.N., Weisz, G.M. \& Waring, E.M. (1978) The relationship of chronic pain to depression, marital adjustment, and family dynamics. Pain, 5, 285.

NeISSER, U. (1976) Cognition and reality: Principles and implications of cognitive psychology. W. H. Freeman, San Francisco.

NEUFELD, R.W J. \& KUIPER, N.A. (1983) Stress-relevant deviance and sources of stress-negotiation difficulties in the medical setting. Canadian Journal of Behavioural Science, 15, 334.

Norton, G.R., Goszer, L., STRUB, H. \& MAN, S.C. (1984) The effects of belief on acupuncture analgesia. Canadian Journal of Behavioural Science, 16, 22.

PILOWSKY, I. (1980) Abnormal illness behavior and sociocultural aspects of pain. In: Pain and Society. (Eds. H. W. Kosterlitz and L.Y. Terenius) Verlag Chemie, Weinheim.

RACHMAN, S. (1980) Emotional processing. Behavior Research and Therapy, 18, 51 .

ReAdiNG, A.E. (1983) The McGill Pain Questionnaire: An appraisal. In: Pain measurement and assessment. (Ed. R. Melzack) Raven Press, New York.

ROBERTS, A.H. \& REINHARDT, L.K. (1980) The behavioral management of chronic pain: Long-term follow-up with comparison groups. Pain, 8, 151.

ROSEnTHAL, T.L. \& Zimmerman, B.J. ((1978) Social learning and cognition. Academic Press, New York.

ShAPIRO, A.K. (1971) Placebo effects in medicine, psychotherapy and psychoanalysis. In: Handbook of psychotherapy and behavior change. (Eds. A. E. Bergin \& S. L. Garfield). Wiley, New York.

SteRnBACH, R.A. (1974) Pain patients: Traits and Treatment. Academic Press, New York.

STERnBaCh, R.A. (Ed.) (1978) The psychology of pain. Raven Press, New York.

TAN, S.Y. (1982) Cognitive and cognitive-behavioral methods for pain control: A selective review. Pain, 12, 201.

TEASDALE, J.D. \& REzIN, V. (1977) Effect of thought-stopping on thoughts, mood and corrugator EMG in depressed patients. Behavior Research and Therapy, 16, 97.

Turk, D.C., Meichenbaum, D. \& Genest, M. (1983) Pain and behavioral medicine. Guilford Press, New York.

WEIMER, W.B. (1982) Hayek's approach to the problems of complex phenomena: An introduction to the theoretical psychology of the sensory order. In: Cognition and the symbolic processes, Vol. 2. Lawrence Erlbaum Associates, Hillside, N.J.

Weisenberg, M. (1983) Pain and pain control. In: Diagnosis and intervention in behaviour therapy and behavioural medicine. (Ed. $R$. J. Daitzman). Springer, New York. 